\title{
Thrombin Generation in Platelet-Rich Plasma as a Tool for the Detection of Hypercoagulability in Young Stroke Patients
}

\author{
C.G. Faber ${ }^{a}$ J. Lodder ${ }^{a}$ F. Kessels ${ }^{b} \quad$ J. Troost ${ }^{a}$ \\ aDepartment of Neurology, University Hospital Maastricht, and ' ${ }^{b}$ Department of Epidemiology, \\ University of Limburg, Maastricht, The Netherlands
}

\section{Key Words}

Platelets $\cdot$ Stroke $\cdot$ Thrombin generation .

von Willebrand factor · Young adults

\begin{abstract}
The time course of the concentration of active thrombin in clotting plasma (the thrombogram) was measured by subsampling from platelet-rich plasma (PRP) and continuous chromogenic measurement of platelet-poor plas$\mathrm{ma}$ (PPP) in 41 stroke patients under the age of 50 , in whom stroke could not be attributed to cardioembolic disease, arterial dissection or vasculitis. A significant increase in the area under the thrombogram (endogenous thrombin potential, ETP) was seen in 23 patients. In 9 of them, ETP was increased in PRP but normal in PPP. High ETP in PRP was significantly associated with stroke, both in the middle and in the highest tercile of the ETP (odds ratio 5.1, range 1.8-15.1, and 3.7, range 1.3-10.3, respectively). A decreased sensitivity to the inhibitory action of thrombomodulin (TM) on thrombin generation was observed in 5 of 37 cases. No further definition of the cause of increased thrombin generation or TM resistance was attempted, except for the role of von Willebrand factor (VWF). ETP in PRP, platelet-derived proco-
\end{abstract}

\section{KARGER}

Fax +41613061234

E-Mail karger@karger.ch

www.karger.com

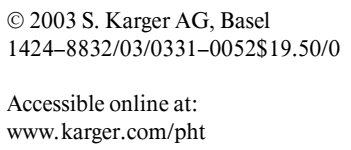

agulant activity and VWF were correlated and higher in patients than in controls $(p=0.002, p=0.045$ and $p=$ 0.0006 , respectively). This confirms the correlation between vWF level and stroke at young age found in epidemiological studies. It suggests that the role of vWF in thrombin generation, which has been demonstrated in vitro, may be the underlying mechanism of this correlation. In summary, hypercoagulability, defined as an increased capacity of the platelet plasma system to form thrombin, is found in over half of the patients under 50 years with an otherwise unexplained stroke. Sometimes it is due to increased plasma factor activity, sometimes to an increased procoagulant activity of the platelets.

Copyright $@ 2003$ S. Karger AG, Basel

\section{Introduction}

Thrombin generation at the lesion site has been shown to be a key event in the pathogenesis of coronary infarction [1]. It is dependent upon the force of the local trigger, i.e. the extent of the lesion, and upon the capacity of the blood to form thrombin. Decreasing this capacity decreases the rate of reinfarction [2,3], while an increase in the capacity to form thrombin, i.e. hypercoaguability as 
defined by Virchow, is assumed to predispose to thrombus formation.

In ischemic stroke, probably the same mechanisms play a role as in coronary infarction. A role of hypercoagulability has not been unequivocally established however. In the literature, such hypercoagulative changes are reported at limited and varying percentages (1-25\%).

Recognizing hypercoagulability would be useful in epidemiological studies and may help to establish secondary preventive medication in the individual patient. Tests in which the overall function of the clotting system is assessed via a clotting time, i.e. (variations of) the (partial) thromboplastin time, have proven to be insensitive to hypercoagulability. The current approach is to search for genes and/or proteins that (may) cause hypercoagulant changes. This policy restricts the search to known causes, such as protein $\mathrm{C}$ deficiency, antithrombin deficiency or lupus anticoagulant.

Alternatively, the thrombin-generating function of the blood can be directly measured from the time course of the thrombin concentration in clotting plasma (the thrombogram). The thrombogram in platelet-poor plasma (PPP) reflects the function of the ensemble of plasmatic pro- and anticoagulant factors. In platelet-rich plasma (PRP), the procoagulant role of platelets and its modifications by antiplatelet agents are also shown (e.g. aspirin, clopidogrel or GPIIb/IIIa blockers). Activation of the protein C pathway by thrombomodulin (TM) decreases thrombin generation, but any impairment in this mechanism will result in significant insensitivity to the TM effect [4]. By determining thrombin generation in PRP and in PPP, in the extrinsic and intrinsic system, and in the presence and absence of TM, the global thrombin-generating function of the blood can be assessed, and the effect can be localized in its most important subsections. It has been reported that thrombin generation is increased in all thrombosis-prone states investigated and decreases with all antithrombotic treatments tested [5].

It is the purpose of this study to check the feasibility of assessing hypercoagulability in stroke patients by measuring thrombin generation. We selected a limited number $(\mathrm{n}=41)$ of patients at an age at which the vessel wall is in general only moderately affected ( $<50$ years), excluding patients with specific anatomic causes (e.g. cardioembolism or dissection), but including all mobile patients irrespective of the type of stroke or laboratory results.

We did not aim to find the cause of the increased thrombin generation more precisely by determining lupus antibodies or individual levels of pro- or anticoagulant factors. However, von Willebrand factor (vWF) levels were assessed, because this broaches an important conceptual item. The observation that high vWF levels are correlated with stroke [6-8] suggests a pathogenetic role for platelet adhesiveness at high shear stress. Recent in vitro experiments have shown, however, that vWF not only has a function in platelet adhesion and as a carrier of factor VIII, it is also required for thrombin generation in PRP via a mechanism in which fibrin and platelet receptor GP1b are involved $[9,10]$. If this third function of $\mathrm{vWF}$ is of pathophysiological importance in stroke, one would expect a relationship between thrombin generation and $\mathrm{vWF}$ levels in our patients.

\section{Materials and Methods}

\section{Patients}

41 patients under age 50 with ischemic stroke were recruited among patients registered between July 1986 and July 1996 in the ongoing prospective Maastricht Stroke registry [11]. Patients with a Rankin score of 5, with a potential source of cardioembolism, with an arterial dissection or with other specific causes of stroke (polycythemia vera, vasculitis or liver cirrhosis) were excluded. Patients stopped taking oral contraceptives after their stroke. Seventy healthy controls were recruited among hospital and university personnel, matched for age and sex. After approval by the medical ethics committee, written informed consent was obtained from patients and controls. Routine investigations in the patient group included standard blood tests, electrocardiogram, brain CT, noninvasive carotid studies and echocardiography. Cerebral angiography was performed in 21 cases for specific individual reasons. Routine laboratory investigations ( $\mathrm{Hb}, \mathrm{Ht}$, leukocyte count and platelet count) were normal. There were 2 patients with anticardiolipin antibodies, and 1 patient with lupus anticoagulant; 6 patients had a hyperhomocysteinemia. Eight patients suffered a recurrent stroke. These patients entered the study after their second stroke. All patients were investigated at least 3 months after the ischemic event. The characteristics of the study cohort are shown in table 1.

\section{Preparation of Plasma}

PRP was obtained 2 weeks after ending all antithrombotic treatment, notably aspirin. Fresh citrated blood ( 9 parts of blood to 1 part of $0.13 \mathrm{~mol} / \mathrm{l}$ trisodium citrate) was centrifuged at $250 \mathrm{~g}, 15^{\circ} \mathrm{C}$ for $10 \mathrm{~min}$. The platelet count was adjusted to $3 \times 10^{8} / \mathrm{ml}$ using autologous PPP (centrifuged for $10 \mathrm{~min}$ at $1,000 \mathrm{~g}$ ). Before storage at $-80^{\circ} \mathrm{C}, \mathrm{PPP}$ was centrifuged twice at $1,000 \mathrm{~g}$ for $10 \mathrm{~min}$. Plasma was defibrinated by adding 1/50 volume of Ancrod and clot dissolution [12]. After the thrombin generation test in PRP had been performed, the remaining serum was put on ice and centrifuged at $15,000 \mathrm{~g}$ for $2 \mathrm{~min}$. The supernatant was stored at $-80^{\circ} \mathrm{C}$. Normal pool plasma was pooled PPP from at least 10 apparently healthy male donors and stored at $-80^{\circ} \mathrm{C}$ for less than 4 months.

\section{Measurement of Thrombin Generation}

Thrombin generation was measured with a subsampling technique, as previously described in detail $[12,13]$. In short, in PRP thrombin was determined by subsampling on the thrombin substrate 
Table 1. Clinical characteristics of young stroke patients and controls

\begin{tabular}{lcl}
\hline & $\begin{array}{l}\text { Patients } \\
\mathrm{n}=41\end{array}$ & $\begin{array}{l}\text { Controls } \\
\mathrm{n}=70\end{array}$ \\
\hline Mean ( \pm SD), years & $43.9( \pm 6.0)$ & $39.5( \pm 8.9)$ \\
Range & $25-50$ & $23-57$ \\
Males & $19(46.3 \%)$ & $33(47.1 \%)$ \\
\hline Medical history & & \\
Prior stroke/TIA & $4(9.8 \%)$ & 0 \\
Myocardial infarction & $3(7.3 \%)$ & 0 \\
Angina pectoris & $5(12.2 \%)$ & 0 \\
Peripheral artery disease & $4(9.8 \%)$ & 0 \\
Hypertension & $19(46.3 \%)$ & $3(4.3 \%)$ \\
Hypertensive medication & $12(29.3 \%)$ & 0 \\
Chronic obstructive pulmonary disease & $3(7.3 \%)$ & $3(4.3 \%)$ \\
Diabetes mellitus & $2(4.9 \%)$ & 0 \\
Hypercholesterolemia & $12(29.3 \%)$ & $1(1.4 \%)$ \\
1st-degree relatives with vascular disease & $24(58.5 \%)$ & $33(47.1 \%)$ \\
Oral contraceptive use & $9(22.0 \%)$ & $10(14.3 \%)$ \\
Smoking & $28(68.3 \%)$ & $20(28.6 \%)$ \\
Use of alcohol & $16(39.0 \%)$ & $58(82.9 \%)$ \\
Alcohol units/week (among users) & $12.4(10.7)$ & $8.1(9.3)$ \\
\hline Stroke type & & \\
Cortical & $23(56.1 \%)$ & \\
Lacunar & $9(22.0 \%)$ & \\
Cerebellar & $1(2.4 \%)$ & \\
Brainstem & $5(12.2 \%)$ & \\
TIA & $3(7.3 \%)$ & \\
& & \\
\hline
\end{tabular}

TIA $=$ Transient ischemic attack.

S2238 and in PPP by monitoring optical density of the pNA released from a slow-reacting chromogenic thrombin substrate (MZ-Aib-ArgpNA or Msc-Val-Arg-pNA and DEMZ-Gly-Arg-pNA) added to the defibrinated plasma upon recalcification. In both methods, the reacting mixture for the measurement of thrombin generation consisted of four parts plasma, one part of buffer containing phospholipid vesicles $(20$ mol- $\%$ phosphatidylserine and 80 mol- $\%$ phosphatidylcholine) and for the extrinsic system: $4 \mu M$ phospholipid with $15 \mathrm{p} M$ recombinant human tissue factor, for the intrinsic system, $4 \mu M$ phospholipid and 1/6 volume of ActinFS ${ }^{\circledR}$ (Dade). The ETP in PPP is expressed as a percentage of the ETP in normal pool plasma measured simultaneously. The ETP in PRP is expressed as a percentage of the control group (median $515 \mathrm{n} M \cdot \min , 25 \mathrm{th}-75$ th percentile: $449-553 \mathrm{n} M \cdot \min )$

\section{TM Test}

To probe the function of the protein $\mathrm{C}$ pathway, the extrinsic thrombin generation test was performed in the presence and absence of soluble recombinant TM. The final concentration of phospholipids was $1 \mu M$, of TM $30 \mathrm{n} M$ and of recombinant tissue factor $2 \mathrm{p} M$. Under these conditions the clotting time of normal pooled plasma in glass was $60 \mathrm{~s}$, and TM causes $40 \%$ inhibition of thrombin genera-
Table 2. Thrombin generation-related parameters

\begin{tabular}{lccc}
\hline & $\begin{array}{l}\text { Controls } \\
\mathrm{n}=70\end{array}$ & $\begin{array}{l}\text { Patients } \\
\mathrm{n}=41\end{array}$ & $\mathrm{p}$ \\
\hline ETP extrinsic, \% & $105(98-113)$ & $106(93-121)$ & $\mathrm{NS}$ \\
ETP intrinsic, \% & $100(91-110)$ & $105(87-122)$ & $\mathrm{NS}$ \\
ETP in PRP, \% $^{\text {PMPA }, \%}$ & $102(89-110)$ & $111(104-188)$ & $<0.01$ \\
vWF, \% $_{\text {Fibrinogen, g/1 }}^{79(65-88)}$ & $90(69-106)$ & $<0.05$ \\
Antithrombin, \% & $86(74-100)$ & $102(87-118)$ & $<0.01$ \\
TM, \% inhibition $^{\mathrm{a}}$ & $108(2.5-3.2)$ & $3.2(2.8-4.0)$ & $<0.01$ \\
& $79(68-88)$ & $81(62-97)$ & $<0.05$ \\
\hline
\end{tabular}

Median values and (25th-75th percentiles).

a Not determined in all subjects.

tion. We avoided the use of 'sensitivity ratios'. The effect of TM in the patient samples is expressed as a percentage of its effect in normal plasma; e.g. if $40 \%$ inhibition is seen in the normal pool plasma and $25 \%$ in a patient, the TM reactivity is defined to be $25 / 40=62.5 \%$ of normal. Due to technical limitations, this test was done in 37 patients and in 24 controls only.

Measurement of Platelet-Derived Procoagulant Activity in Serum

The platelet-membrane-derived procoagulant phospholipid activity (PMPA) was determined according to Béguin et al. [14]. PMPA was determined in 34 patients and in 52 controls.

\section{Statistical Evaluation}

Variables are presented as medians and 25 and 75 percentiles. We used the Kendall's $\tau$ to determine correlation, and the Mann-Whitney test to analyze differences in distribution between groups. We analyzed the association between stroke and ETP in PRP and PPP by means of odds ratios (OR) with $95 \%$ confidence intervals (CI) in a logistic regression model. For the logistic regression analysis, patients were categorized in groups using cutoff points at the 33rd and 66th percentiles of the value of the ETP in PPP. To determine whether patients with a normal extrinsic ETP would have a platelet-related enhanced ETP, these patients were divided into three groups on the basis of the ETP values in PRP (33rd and 66th percentiles). We analyzed the relationships between ETP in PRP, PMPA, vWF and fibrinogen using linear regression analysis. To check whether relationships were different for patients and controls, we also performed linear regression analysis separately for patients and controls. Results of linear regression analysis are presented as regression coefficients with $95 \%$ CIs.

In the TM test, we considered a percentage inhibition below the 5 th percentile of the control group (this was a percentage inhibition of less than $57 \%$ of the ETP after addition of TM) as an insufficient reaction to $\mathrm{TM}$. We analyzed the association between stroke and the results of the TM test by means of ORs with $95 \%$ CIs in a logistic regression model. 
Table 3. Thrombin-generation-related parameters in subgroups

\begin{tabular}{|c|c|c|c|c|}
\hline & $\begin{array}{l}\text { Controls } \\
n=70\end{array}$ & $\begin{array}{l}\text { Group } 1 \\
(\text { ETP }>118) \\
n=9\end{array}$ & $\begin{array}{l}\text { Group } 2 \\
\text { (ETP 111-117) } \\
\mathrm{n}=10\end{array}$ & $\begin{array}{l}\text { Group } 3 \\
(\text { ETP }<110) \\
n=8\end{array}$ \\
\hline ETP in PRP & $102(89-110)$ & $124(119-134)^{\mathrm{a}}$ & $113(111-115)^{\mathrm{a}}$ & $94(81-103) \mathrm{NS}$ \\
\hline PMPA & $79(65-88)$ & $107(78-117)^{b}$ & 91 (72-99) NS & $50(45-100) \mathrm{NS}$ \\
\hline vWF & $86(74-100)$ & $102(92-138)^{\mathrm{c}}$ & $100(91-113)^{\mathrm{c}}$ & $97(73-124) \mathrm{NS}$ \\
\hline Fibrinogen & $2.8(2.5-3.2)$ & $3.3(3.0-3.8)^{\mathrm{c}}$ & $3.5(2.7-3.9)^{b}$ & $2.9(2.2-3.2) \mathrm{NS}$ \\
\hline
\end{tabular}

${ }^{\mathrm{a}} \mathrm{p}<0.001 ;{ }^{\mathrm{b}} \mathrm{p}<0.01 ;{ }^{\mathrm{c}} \mathrm{p}<0.05$. PMPA was not determined in all subjects. Medians (25th-75th percentiles).

\section{Results}

\section{Thrombin Generation in PPP}

In the patient group, the mean thrombin generation in PPP did not significantly differ compared to the controls, either when triggered by tissue factor (extrinsically) or by contact activation (intrinsically; table 2). In the patients, however, the values were not normally distributed, which was seen when the results were divided into three groups along the 33rd and 66th percentile boundaries of the normal controls (fig. 1). A significantly high number of patients were above the 66 th percentile border or below the 33 rd percentile limit. It thus seems that hypercoagulability is found in a subgroup of patients, but that its effect on the mean is compensated for by a larger amount of patients who exhibit low thrombin generation.

There was a significant correlation between ETP in the intrinsic and in the extrinsic system (Kendall's $\tau 0.57, \mathrm{p}<$ 0.001 ), and analysis of the data in terms of intrinsic thrombin generation did not show essentially different results, the above 66th percentile group being one larger (results not shown). We used only the results in the extrinsic system for classification (table 3).

Patients who suffered a recurrent stroke $(n=8)$ had a significantly higher ETP in the extrinsic pathway (119, $110-136$, vs. $102,90-121, p=0.03$; OR $3.1,95 \%$ CI $1.1-$ 8.5). Patients with peripheral artery disease $(n=4)$ also had higher ETP in PPP compared with other patients (extrinsic 123, 111-136, intrinsic 133, 116-168, $p=0.03$ and $\mathrm{p}=0.02$, respectively). Using the Mann-Whitney test, no significant differences were found between patients with or without ischemic heart disease, hypertension, hyperhomocysteinemia, diabetes or current smoking.

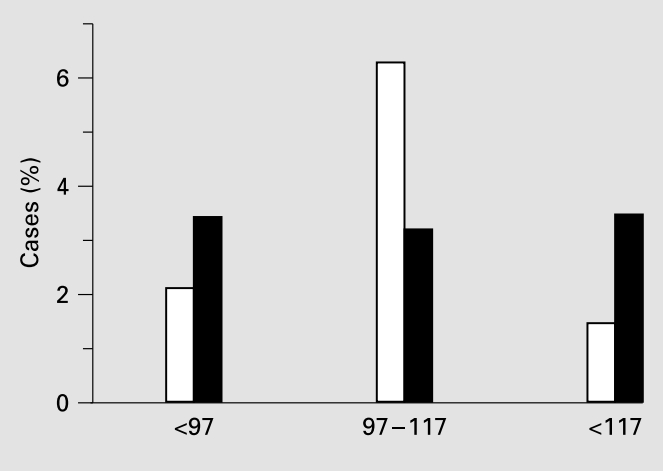

Fig. 1. Repartition of ETP values over the 33 and 66 percentile values of the normal subjects. $\square=$ Normals; $\square$ = patients.

\section{Thrombin Generation in PRP}

In contrast to thrombin generation in PPP, mean thrombin generation in PRP is significantly higher in stroke patients than in controls (table 2).

To determine whether patients with a normal extrinsic ETP $(n=27)$ would have a platelet-related enhanced ETP, these patients were divided into three groups on the basis of the ETP values in PPP (33rd and 66th percentiles). The distribution of patients among the different categories is presented in diagram form in figure 2.

The results of the ETP in PRP in the separate groups are shown in table 3. ETP in PRP was significantly associated with stroke, both in the group with intermediate and high ETP (OR 5.1 and 3.0, 95\% CI 1.8-15.1 and 1.3-8.1, respectively). With the combined results of the ETP in PPP and in PRP, patients can be divided into a group with suspected abnormalities in the plasmatic coagulation system $(n=14)$, a group with platelet-related hypercoagu- 


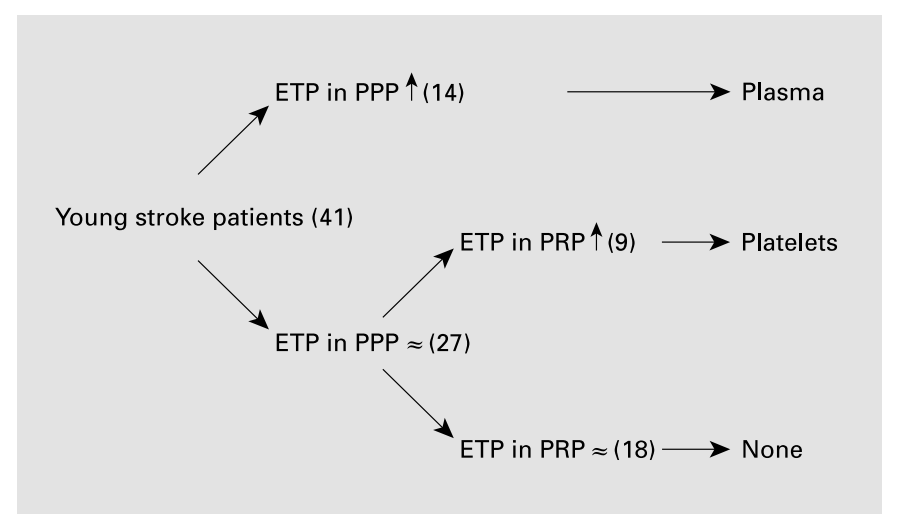

Fig. 2. Localization of hypercoagulability in the patient population. $\uparrow=$ Increase; $\approx=$ normal value).

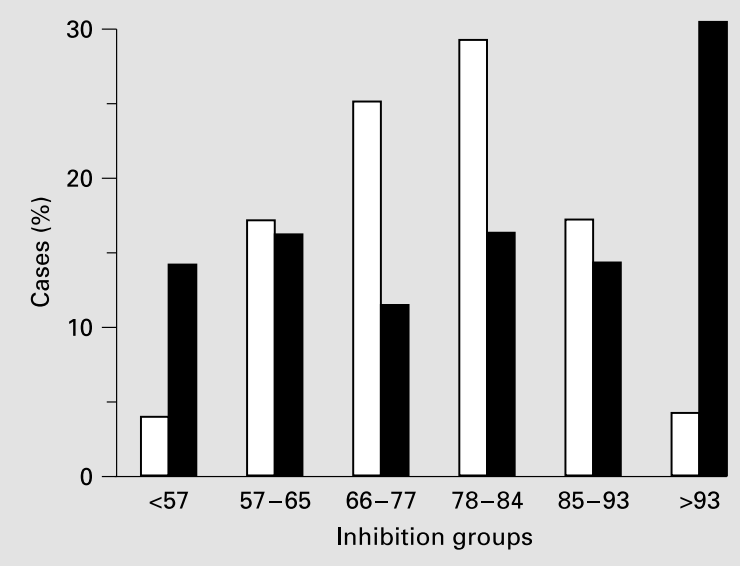

Fig. 3. Repartition of TM-induced inhibition. $\square=$ Normals patients.

lability $(\mathrm{n}=9)$ and a group with no coagulation abnormalities ( $\mathrm{n}=18$; fig. 2). It thus seems that apart from the clotting system per se, the platelets can also contribute to a hypercoagulable state. This is further corroborated by the fact that PMPA in the serum was significantly higher in the patient group than in the controls (table 2).

\section{Relationship of ETP, $v W F$ and PMPA}

In search for a possible cause of platelet-related hypercoagulability, we determined two plasma factors that are known to enhance this activity: fibrinogen and $\mathrm{vWF}$. The group with the highest ETP in PRP (group 1) also had higher vWF, PMPA, and fibrinogen levels than the con-
Table 4. Linear regression analysis of ETP in PRP with related parameters

\begin{tabular}{|c|c|c|c|c|}
\hline & Regression model & Controls & Patients & Overall \\
\hline 1 & $\begin{array}{l}\text { Dependent PMPA } \\
\text { Independent vWF }\end{array}$ & $\begin{array}{l}0.16 \\
(-0.06-0.39)\end{array}$ & $\begin{array}{l}0.23 \\
(-0.07-0.53)\end{array}$ & $\begin{array}{l}0.23^{\mathrm{c}} \\
(0.05-0.40)\end{array}$ \\
\hline 2 & $\begin{array}{l}\text { Dependent ETP } \\
\text { Independent PMPA }\end{array}$ & $\begin{array}{l}2.07^{\mathrm{b}} \\
(0.83-3.31)\end{array}$ & $\begin{array}{l}2.05^{\mathrm{a}} \\
(1.08-3.02)\end{array}$ & $\begin{array}{l}2.11^{\mathrm{a}} \\
(1.32-2.89)\end{array}$ \\
\hline 3 & $\begin{array}{l}\text { Dependent ETP } \\
\text { Independent vWF }\end{array}$ & $\begin{array}{l}0.99 \\
(-0.03-2.03)\end{array}$ & $\begin{array}{l}0.91^{\mathrm{c}} \\
(0.02-1.79)\end{array}$ & $\begin{array}{l}1.16^{\mathrm{a}} \\
(0.49-1.84)\end{array}$ \\
\hline
\end{tabular}

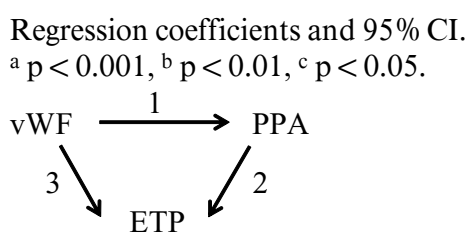

Presumed relationships between vWF, PPA and ETP in PRP.

trols. In the group with a moderate increase in ETP (group 2), both ETP and vWF were higher than in controls. PMPA in this group was also higher, though not statistically significant. The group with the lowest ETP in PRP (group 3) did not differ from the controls.

In a regression model with ETP as dependent and $\mathrm{vWF}$ as independent variable, vWF was significantly associated with the ETP (table 4), and PMPA was strongly associated with the ETP, but fibrinogen was not associated with the ETP in PRP. In a regression model with PMPA as dependent variable, vWF was a significant predictor of elevation of PMPA (table 4). There were no significant differences between patients with territorial or lacunar infarcts, with respect to ETP in PRP, PMPA and vWF. There was no relationship between ETP in PRP and age, ischemic heart disease, hypercholesterolemia or diabetes. There was a significant correlation between ETP in PRP and hypertension $(\mathrm{p}=0.04)$.

\section{The Protein C Pathway}

There were 5 patients, all female, with lower than normal inhibition of the ETP after addition of TM $(13,32$, 45,48 and $56 \%$ of normal control, respectively; figure 3 ). In a logistic regression model, an insufficient inhibition in the TM test was significantly associated with stroke (OR 9.9; 95\% CI 1.1-87.6). Four of these patients had a normal ETP. Three of these patients used oral contraceptives at the time of the ischemic event (all patients stopped oral contraceptive use after their stroke), and 4 smoked cigarettes. Two of them had hyperhomocysteinemia. 


\section{Discussion}

In previous studies, specific causes that are known to increase thrombin generation are sometimes found to be a risk factor for stroke (prothrombin level [15]) and sometimes not (activated protein C resistance [16, 17], anticardiolipin antibodies [18]). The incidence of procoagulant disturbances in a population of stroke patients (i.e. deficiencies in antithrombin or heparin cofactor II, proteins $\mathrm{S}$ and $\mathrm{C}$, activated protein $\mathrm{C}$ resistance, anticardiolipin antibodies or lupus anticoagulant) is sometimes found to be as high as $25 \%$ [19] whereas others find no evidence for differences within a control group [20].

Searching for hypercoagulability via searching recognized underlying disorders restricts the search to a set of defined single genes and/or proteins and excludes finding hypercoagulability due to unknown or combined causes. We therefore preferred to investigate the output side of the coagulation mechanism and investigated whether increased generation of thrombin contributes to the development of stroke. A role of hypercoagulability, if any, will be clearest in a group of patients in whom local causes of the disease are minimal. We therefore restricted our search to a group of patients aged $<50$ years in whom anatomical reasons for stroke had been excluded, so that atherosclerotic lesions on the mean are not far advanced.

Our results lead to the conclusion that increased thrombin generation is more frequent in this group of stroke patients than in matched normal controls. One can infer that it will probably be found to a lesser extent in the bulk of patients, but further epidemiological studies are required. Recently, large-scale studies became possible through developments in the technique of measuring thrombin generation in PRP [21].

Thrombin generation in PRP reflects the combined activity of the complete set of plasmatic clotting factors and of blood platelets and thus screens the broadest spectrum of reactants, so it is not surprising that significant changes in ETP are most readily encountered in this test, i.e. in more than half of the patients. The statistical model shows that an intermediate or high ETP in PRP is a predictor of stroke. Thrombin generation in PPP is high in a subgroup of our patients, but mean values are not increased (fig. 1). A striking finding was that patients with recurrent stroke did have significantly higher ETP in PPP than those without. This suggests that in multiple stroke patients, the systemic component may be more important than in single stroke, which stands to reason.

The fact that we found a group in which the reaction in PPP was normal but elevated in PRP suggests specific pathogenic mechanisms for platelet-based hypercoagulability that have not yet been found to our knowledge. From the type of screening reported here, individuals or families can be identified following further investigation.

Two plasmatic factors influence the procoagulant function of platelets: vWF and fibrinogen. vWF mediates the interaction between fibrin and platelets through $\mathrm{GPIb}$ [22-24], which is one of the pathways that renders platelets procoagulant [9]. Earlier studies demonstrated a correlation between $\mathrm{vWF}$ and cerebrovascular disease [6-8]. In our patients, $\mathrm{vWF}$ was increased and we found a significant correlation between ETP in PRP and $\mathrm{vWF}$, as well as between PMPA and vWF. This indicates that vWF is not merely a marker of endothelial damage but plays an instrumental role in thrombin generation. Our findings suggest a mechanistic explanation for the epidemiologically demonstrated relationship between increased vWF and stroke c.q. mortality in stroke survivors.

Fibrinogen is an independent risk factor for stroke and myocardial infarction [25-27], and fibrin induces platelet procoagulant activity [9]. Fibrinogen (and thus fibrin) was indeed elevated in our patients, but we found no correlation between the fibrinogen level and ETP in PRP. This may be because the fibrin clot that formed in the thrombin generation experiments for technical reasons was discarded as soon as possible, so that it was only present during the initial phase of thrombin formation. Also, the fact that fibrin adsorbs thrombin may lead to underestimation of thrombin generation at high fibrinogen levels.

The inhibitory effect of TM on thrombin generation is dependent upon a normal function of the protein $\mathrm{C}$ pathway [4]. The inhibition by TM (or activated protein C) can also be attenuated by lupus-related antibodies and by hormonal changes (e.g. use of oral contraceptives) [28, 29]. Our 5 patients with a low sensitivity to TM all had one or more additional vascular risk factors at the moment of the stroke. This concurs with the finding that the increased risk of myocardial infarction in women with the factor $\mathrm{V}_{\text {Leiden }}$ mutation was largely confined to those with an additional risk factor (smokers) [30].

We investigated only patients who were able and willing to come to the hospital. and who were therefore functionally less affected than the patient population from which they were recruited. If there exists a relationship between hypercoagulability and the degree of neurological deficit, the strength of the association between the hypercoagulability and stroke would have been underestimated in our population. Notwithstanding, our study suggests that hypercoagulability is far more important in young stroke patients than so far assumed. 
Thrombin generation measurement in PRP and in PPP theoretically offers the possibility to differentiate between plasma based- and platelet-related hypercoagulability. Secondary prevention with anticoagulants might be indicated in patients with plasma-based hypercoagulability, whereas antiplatelet drugs are the logical choice if the ETP is high in PRP only. Clinical studies are needed to validate this concept.

\section{Acknowledgments}

The study presented in this paper was financially supported by a grant from the University Hospital Maastricht Fund for outstanding and competitive clinical research ('het Profileringsfonds'). We thank Suzette Béguin and Coen Hemker for their help in planning and reporting this work and Paul Devilée, Simone Wielders and Khaled Maroofi for their technical assistance. We are indebted to Karli Hamulyàk for his kind support.

\section{References}

1 Badimon L, Meyer BJ, Badimon JJ: Thrombin in arterial thrombosis. Haemostasis 1994;24: 69-80.

2 A double-blind trial to assess long-term oral anticoagulant therapy in elderly patients after myocardial infarction. Report of the Sixty Plus Reinfarction Study Research Group. Lancet 1980;2:989-994.

3 Neri Serneri GG, Rovelli F, Gensini GF, Pirelli S, Carnovali M, Fortini A: Effectiveness of lowdose heparin in prevention of myocardial reinfarction. Lancet 1987;i:937-942.

4 Duchemin J, Pittet JL, Tartary M, Beguin S, Gaussem P, Alhenc-Gelas M, Aiach M: A new assay based on thrombin generation inhibition to detect both protein $\mathrm{C}$ and protein $\mathrm{S}$ deficiencies in plasma. Thromb Haemost 1994;71: 331-338.

5 Hemker HC, Beguin S: Phenotyping the clotting system. Thromb Haemost 2000;84:747751.

6 Qizilbash N, Duffy S, Prentice CRM, Boothby M, Warlow C: Von Willebrand factor and risk of ischemic stroke. Neurology 1997;49:15521556.

7 Kario K, Matsuo T, Kobayashi H, Asada R, Matsuo M: 'Silent' cerebral infarction is associated with hypercoagulability, endothelial cell damage, and high Lp(a) levels in elderly Japanese. Arterioscler Thromb Vasc Biol 1996;16: 734-741.

8 Catto AJ, Carter AM, Barrett JH, Bamford J, Rice PJ, Grant PJ: von Willebrand factor and factor VIII: $\mathrm{C}$ in acute cerebrovascular disease. Relationship to stroke subtype and mortality. Thromb Haemost 1997;77:1104-1108.

9 Kumar R, Beguin S, Hemker HC: The effect of fibrin clots and clot-bound thrombin on the development of platelet procoagulant activity. Thromb Haemost 1995;74:962-968.

10 Beguin S, Kumar R: Thrombin, fibrin and platelets: A resonance loop in which von Willebrand factor is a necessary link. Thromb Haemost 1997;78:590-594.

11 van Zagten M, Boiten J, Kessels F, Lodder J: Significant progression of white matter lesions and small deep (lacunar) infarcts in patients with stroke. Arch Neurol 1996;53:650-655.
12 Wielders S, Mukherjee M, Michiels J, Rijkers DTS, Cambus JP, Knebel RWC, Kakkar V, Hemker HC, Beguin S: The routine determination of the endogenous thrombin potential, first results in different forms of hyper- and hypocoagulability. Thromb Haemost 1997;77: 629-636.

13 Beguin S, Lindhout T, Hemker HC: The effect of trace amounts of tissue factor on thrombin generation in platelet rich plasma, its inhibition by heparin. Thromb Haemost 1989;61: 25-29.

14 Beguin S, Kumar R, Keularts I, Seligsohn U, Coller BS, Hemker HC: Fibrin-dependent platelet procoagulant activity requires GPIb receptors and von Willebrand factor. Blood 1999;93:564-570.

15 De Stefano V, Chiusolo P, Paciaroni K, Casorelli I, Rossi E, Molinari M, Servidei S, Tonali PA, Leone G: Prothrombin G20210A mutant genotype is a risk factor for cerebrovascular ischemic disease in young patients. Blood 1998;91:3562-3565.

16 Sanchez J, Roman J, Delatorre MJ, Velasco F, Torres A: Low prevalence of the factor V Leiden among patients with ischemic stroke. Haemostasis 1997;27:9-15.

17 Halbmayer WM, Haushofer A, Angerer V, Finsterer J, Fischer M: APC resistance and factor $\mathrm{V}$ Leiden [FV Q(506)] mutation in patients with ischemic cerebral events. Blood Coagul Fibrinolysis 1997;8:361-364.

18 Muir KW, Squire IB, Alwan W, Lees KR: Anticardiolipin antibodies in an unselected stroke population. Lancet 1994;344:452-456.

19 Munts AG, van Genderen PJJ, Dippel DWJ, van Kooten F, Koudstaal PJ: Coagulation disorders in young adults with acute cerebral ischaemia. J Neurol 1998;245:21-25.

20 Tosetto A, Ruggeri M, Castaman G, Rodeghiero F: Inherited abnormalities of blood coagulation in juvenile stroke: A case control study. Blood Coagul Fibrinolysis 1997;8:397-402.

21 Hemker HC, Giesen PL, Ramjee M, Wagenvoord $\mathrm{R}$, Beguin $\mathrm{S}$ : The thrombogram: Monitoring thrombin generation in platelet rich plasma. Thromb Haemost 2000;83:589-591.
22 Loscalzo J, Inbal A, Handin RI: von Willebrand protein facilitates platelet incorporation in polymerizing fibrin. J Clin Invest 1986;78: 1112-1119.

23 Jen CJ, Hu SJ, Wu HJ, Lin TS, Mao CW: Platelet-fibrin interaction in the suspension and under flow conditions. Adv Exp Med Biol 1990; 281:277-285.

24 Hantgan RR, Hindriks G, Taylor RG, Sixma JJ, de Groot PG: Glycoprotein Ib, von Willebrand factor, and glycoprotein IIb-IIIa are all involved in platelet adhesion to fibrin in flowing whole blood. Blood 1990;76:345-353.

25 Wilhelmsen L, Svardsudd K, Korsan-Bengtsen K, Larsson B, Welin L, Tibblin G: Fibrinogen as a risk factor for stroke and myocardial infarction. N Engl J Med 1984;311:501-505.

26 Kannel WB, Wolf PA, Castelli WP, D'Agostino RB: Fibrinogen and risk of cardiovascular disease. The Framingham Study. JAMA 1987; 258:1183-1186.

27 Qizilbash N, Jones L, Warlow C, Mann J: Fibrinogen and lipid concentrations as risk factors for transient ischaemic attacks and minor ischaemic strokes. BMJ 1991;303:605-609.

28 Rosing J, Tans G, Nicolaes GA, Thomassen MC, Van Oerle R, van der Ploeg PM, Heijnen P, Hamulyak K, Hemker HC: Oral contraceptives and venous thrombosis: Different sensitivities to activated protein $\mathrm{C}$ in women using second- and third-generation oral contraceptives. Br J Haematol 1997;97:233-238.

29 Regnault V, Béguin S, Wahl D, de Maistre E, Hemker HC, Lecompte T: Thrombinography shows acquired resistance to activated protein $\mathrm{C}$ in patients with lupus anticoagulants. Thromb Haemost 2003;89:208-212.

30 Rosendaal FR, Siscovick DS, Schwartz SM, Beverly RK, Psaty BM, Longstreth WT Jr, Raghunathan TE, Koepsell TD, Reitsma PH: Factor V Leiden (resistance to activated protein $\mathrm{C}$ ) increases the risk of myocardial infarction in young women. Blood 1997;89:28172821 . 